\title{
CONTROLE E CONDIÇÕES CLIMÁTICAS FAVORÁVEIS À ANTRACNOSE DO MAMOEIRO
}

\author{
JOSELI S. TATAGIBA ${ }^{1 *}$, JOSÉ R. LIBERATO ${ }^{2}$, LAÉRCIO ZAMBOLIM ${ }^{2}$, \\ JOSÉ A. VENTURA ${ }^{1} \&$ HÉLCIO COSTA ${ }^{1}$
}

\begin{abstract}
${ }^{1}$ Instituto Capixaba de Pesquisa, Assistência Técnica e Extensão Rural, Cx.Postal 62, CEP 29900-970,
Linhares,ES, fax (27) 3264-3342, e-mail joseli@incaper.es.gov.br; '2Departamento de Fitopatologia,

Universidade Federal de Viçosa, CEP 36571-000, Viçosa, MG
\end{abstract}

(Aceito para publicação em 31/01/2002)

Autor para correspondência: Joseli S. Tatagiba

TATAGIBA, J.S., LIBERATO, J.R., ZAMBOLIM,L., VENTURA, J.A. \& COSTA, H. Controle e condições climáticas favoráveis à antracnose do mamoeiro. Fitopatologia Brasileira 27:186-192. 2002.

RESUMO

\begin{abstract}
A podridão peduncular (PP) e a antracnose são as principais doenças pós-colheita do mamão (Carica papaya). Avaliou-se o efeito de 11 tratamentos (mg. $\mathrm{l}^{-1}$ i.a.) em seu controle: 1chlorothalonil PM (1500); 2-chlorothalonil SC (2000); 3chlorothalonil + oxicloreto de cobre PM $(875+1050)$; 4-tiofanato metílico + chlorothalonil PM $(400+1000) ;$ 5-tiofanato metílico PM (700); 6-tolylfluanid PM (750); 7-tebuconazole CE (200); 8triadimenol CE (250); 9-fluazinam SC (500); 10-iminoctadine F (300) e 11-testemunha. Utilizou-se delineamento em blocos casualizados com quatro repetições e oito plantas / parcela, em pomar de 'Improved Sunrise Solo Line 72/12', em Linhares-ES. De março de 1997 até março de 1998, realizaram-se pulverizações bissemanal a mensalmente e, a partir de setembro, 12 colheitas de nove frutos / parcela. Dez a 12 dias após a colheita, avaliou-se a
\end{abstract}

incidência da antracnose e da PP e a severidade da antracnose, com o uso de escala de notas de 0 a 4 . A incidência da antracnose variou de 68,5 a $100 \%$ na testemunha. A correlação entre incidência e severidade da antracnose foi alta $(r=0,86)$. $O$ uso de fungicidas não reduziu a incidência de PP. Exceto os tratamentos 7 e 8 , os demais reduziram 26,4 a 41,2\% a média geral da incidência de antracnose, em relação à testemunha. Não houve interação entre tratamentos e épocas de avaliação. Houve redução de até 73,6\% da incidência de antracnose. A maior incidência da antracnose e a menor eficiência dos fungicidas ocorreu de novembro a 15 de janeiro, quando ocorreu maior quantidade de chuva $(505 \mathrm{~mm} \mathrm{em}$ 16 dias).

Palavras-chave adicionais: Carica papaya, Colletotrichum gloeosporioides, fungicidas.

\section{ABSTRACT \\ Control and favourable weather for anthracnose of papaya}

Anthracnose and stem-end rot (SER) are the main post harvest diseases of papaya (Carica papaya) in Brazil. The effectiveness of 11 treatments (mg. $\mathrm{l}^{-1}$ a.i.) on the their control was evaluated: 1chlorothalonil WP (1500); 2-chlorothalonil SC (2000); 3-chlorothalonil + copper oxychloride WP $(875$ + 1050); 4-thiofanate-metil + chlorothalonil WP $(400+1000)$; 5- thiofanate-metil WP (700); 6tolylfluanid WP (750); 7-tebuconazole EC (200); 8-triadimenol EC (250); 9-fluazinam SC (500); 10-iminoctadine F (300) and 11unsprayed control. A trial was arranged in a completely randomized block design with four replications and eight plants / plot, using 'Improved Sunrise Solo Line 72/12', in Linhares-ES. From the beginning of flowering (March 1997) to March 1998, biweekly to monthlly sprays were applied. From September on, 12 harvests of nine fruits/plot were accomplished. Ten to 12 days after the harvest, the incidence of anthracnose and SER was evaluated and the severity of anthracnose was estimated visually using a scale from 0 to 4 . The correlation between incidence and severity of anthracnose was high ( $\mathrm{r}$ $=0,86)$. The use of fungicides did not reduce the incidence of SER. Except for treatments 7 and 8, the average incidence was reduced from 26,4 to $41,2 \%$ compared to unsprayed controls. On the third day of evaluation fungicides reduced the anthracnose incidence up to $73,6 \%$. The highest anthracnose incidence and the lowest degree of fungicide effectiveness occurred between November and January $15^{\text {th }}$, which correspond to the highest rain frequency (505 $\mathrm{mm}$ in 16 days).

\section{INTRODUÇÃO}

O Brasil possui cerca de 40.000 ha cultivados com mamoeiro (Carica papaya L.) (FAO, 2000), sendo o Estado do Espírito Santo um dos seus principais produtores e exportadores. Embora o Brasil seja o maior produtor mundial, exporta

\footnotetext{
$\overline{* \text { Bolsista do } \mathrm{CNPq}}$
}

menos de $1 \%$ de sua produção, que correspondeu a $11 \%$ do comércio internacional de mamão, em 1999 (FAO, 2000). Um dos principais fatores limitantes à exportação de mamão são as doenças pós-colheita, principalmente a antracnose causada por Colletotrichum gloeosporioides Penz. e a podridão peduncular, causada por diversos fungos (Alvarez \& Nishijima, 1987), principalmente por C. gloeosporioides e Phoma caricae-papayae (Tar) Punith. (=Ascochyta caricae 
Pat.) (Bolkan et al., 1976; Liberato \& Tatagiba, 2001). Na ausência de medidas de controle, a incidência pode chegar a $91 \%$ de antracnose e $100 \%$ de podridão peduncular, em frutos após a colheita (Liberato \& Costa, 1997).

O mamão se desenvolve durante aproximadamente cinco a seis meses, sendo, na maior parte desse tempo, susceptível a C. gloeosporioides (Dickman \& Alvarez, 1983; Durán et al., 1999), que pode infetar frutos fisiologicamente imaturos e permanecer no estado quiescente até o fruto atingir a fase climatérica (Dickman \& Alvarez, 1983), quando então, em pomares comerciais, o fruto já foi colhido. Assim, a infecção que ocorreu no campo dificilmente é detectada até a colheita, pois os sintomas da antracnose normalmente surgem durante ou após o transporte dos frutos para os mercados consumidores.

Não existem cultivares comerciais resistentes à doença. Medidas de controle visando a redução da incidência da antracnose em frutos devem ser iniciadas no campo (Alvarez \& Nishijima, 1987), sendo considerada como a mais efetiva, pulverizações periódicas a partir de seis a oito meses após o plantio, com intervalos de sete a 14 dias em períodos chuvosos e de 14 a 30 dias em períodos secos (Alvarez \& Nishijima, 1987; Marin et al., 1995).

Tendo em vista que os fungicidas, atualmente registrados no país para uso em pomares de mamoeiro, não controlam satisfatoriamente a antracnose, procurou-se, neste trabalho, avaliar a eficiência de diversos fungicidas, aplicados no campo, no controle dessa doença em frutos, após a colheita, e monitorar as condições meteorológicas para relacioná-las com a intensidade da doença.

\section{MATERIAL E MÉTODOS}

O experimento foi conduzido em uma lavoura do cv. 'Improved Sunrise Solo Line 72/12', plantada em fileira dupla, no espaçamento de 3,3 × 1,8 x 1,8 m, no município de Linhares, ES.

O delineamento experimental foi em blocos casualizados com 11 tratamentos e quatro repetições. A parcela experimental foi constituída por oito plantas, quatro em cada fila. As fileiras duplas vizinhas constituíram a bordadura, assim como quatro plantas entre parcelas na mesma fileira dupla. Os tratamentos constituíram-se dos fungicidas: chlorothalonil PM (1500 mg..$^{-1}$ i.a.); chlorothalonil SC (2000 mg. $1^{-1}$ i.a.); chlorothalonil + oxicloreto de cobre PM (875 + $1050 \mathrm{mg} . .^{-1}$ i.a.); tiofanato metílico + chlorothalonil PM (400 + 1000 mg. l $^{-1}$ i.a.); tiofanato metílico PM (700 mg..$^{-1}$ i.a.); tolylfluanid PM (750 mg..$^{-1}$ i.a.); tebuconazole CE (200 mg. $\mathrm{l}^{-}$ ${ }^{1}$ i.a.); triadimenol CE (250 mg. ${ }^{-1}$ i.a.); fluazinam SC (500 mg. $\mathrm{l}^{-1}$ i.a.); iminoctadine F (300 mg..$^{-1}$ i.a.) e uma testemunha sem pulverização.

Em março de 1997, cerca de quatro meses após o transplantio das mudas no campo, quando se iniciou o desenvolvimento dos frutos, tiveram início as pulverizações das caldas fungicidas, adicionadas de Extravon $\AA(0,02 \% \mathrm{v} /$ v), que perduraram até março de 1998. As datas julianas das aplicações foram: 84, 99, 129, 142, 173, 185, 206, 239, 269, 283, 297, 314, 328, 350 e 364, em 1997, e 13, 27, 41, 57 e 71, em 1998. As aplicações foram dirigidas para o ápice das plantas visando atingir as folhas e os frutos, utilizando-se um pulverizador costal motorizado Óleo Mac $®$ modelo AM 180. O volume de calda utilizado foi $200 \mathrm{a} 300 \mathrm{ml}$ por planta, equivalente a 436-654 1.ha ${ }^{-1}$.

Em julho de 1997, quando iniciou a maturação de frutos, teve início a colheita na testemunha, para avaliação da incidência (percentagem de frutos doentes) da antracnose e da podridão peduncular e da severidade da antracnose, avaliada com o uso de chave descritiva, com os seguintes graus de doença: $0=0 \% ; 1=>0$ a $12,5 \% ; 2=>12,5$ a $25 \% ; 3=$ $>25$ a $50 \%$ e $4=>50 \%$ da face mais lesionada do fruto coberta com lesões. Bissemanalmente coletaram-se nove frutos por parcela, no estádio de maturação (índice de cor da casca) entre 2 e 4, segundo a escala proposta por Balbino (1997), os quais foram acondicionados em caixas de madeira e mantidos em condições de laboratório. Após dez a 12 dias, avaliou-se a intensidade da antracnose e da podridão peduncular. Quando a testemunha passou a apresentar incidência de antracnose, nos frutos, superior a 50\%, o que ocorreu a partir de setembro de 1997, iniciaram-se as colheitas bissemanais de frutos nas parcelas dos demais tratamentos. Foram realizadas 12 colheitas, sempre uma semana após cada aplicação de fungicida. As datas de colheitas de frutos para quantificação das doenças foram denominadas épocas de avaliação.

A coleta dos dados meteorológicos foi realizada com o uso de um pluviômetro, localizado a $200 \mathrm{~m}$ da área experimenta, e de um termo-higro-humectógrafo G.Lufft ${ }^{\circledR}$ modelo 8341, colocado em um abrigo meteorológico, localizado entre as plantas de mamoeiro, à altura de $1,5 \mathrm{~m}$. O sensor de molhamento foi colocado próximo ao centro da coluna de frutos da planta.

O efeito dos tratamentos e das épocas de avaliação na intensidade das doenças foram determinados pela análise de medidas repetidas (Statsoft, 2000), na qual considerou-se o experimento como tendo delineamento em parcelas subdivididas, onde os 11 tratamentos constituíram as parcelas e as 12 épocas de coleta de frutos, para avaliação de doenças, constituíram as subparcelas. Essas análises foram processadas com o programa "Statistica for Windows 5.5" (Statsoft, 2000). Também foram feitas análises de correlação linear simples entre a incidência e a severidade de antracnose e a incidência de podridão peduncular.

\section{RESULTADOS E DISCUSSÃO}

\section{Associação entre incidência e severidade de antracnose em mamão e incidência de podridão peduncular}

Tem sido recomendado que a intensidade de doenças seja avaliada como incidência, por ser mais rápida e acurada, preferencialmente à severidade, nos casos em que uma única lesão é suficiente para impedir a comercialização do produto vegetal, como é o caso de frutos de mamão destinados à exportação. No presente estudo, estimou-se também a severidade 
da antracnose, visando obter uma medida que permitisse diferenciar efeitos de tratamentos, caso isso não fosse possível pela incidência. Ou seja, sob condições de alta densidade de inóculo no campo, se aplicações de determinado fungicida não reduzisse a incidência de antracnose nos frutos, mas reduzisse o número de lesões quiescentes no fruto, em nível de campo, tal fungicida poderia ter potencial de ser utilizado no manejo integrado da doença, associado a medidas de tratamento em pós-colheita.

Pela análise de correlação linear simples, baseada nas médias dos tratamentos e considerando os dados das 12 épocas de avaliação, foram estimados os seguintes coeficientes de correlação: entre incidência e severidade de antracnose em frutos de mamão: $r=0,86$ (Figura 1); entre incidência de antracnose e incidência de podridão peduncular: $r=0,62$; entre severidade de antracnose e incidência de podridão peduncular: $r=0,42$. Esses coeficientes de correlação foram estimados a partir de todas as médias (132 pares de dados). Destas médias, 121 (92\%) correspondem a grau de doença inferior a dois e 127 (96,2\%) apresentaram-se distribuídas, com relativa uniformidade, entre valores de incidência de 30 a $100 \%$ (Figura 1). Isto revela a possibilidade de não ocorrer alta correlação entre a incidência e a severidade da antracnose nas situações em que predominar alta severidade da doença; como por exemplo, grau de doença acima de dois, na escala aqui adotada. Seem (1984) relata que já foi observada alta correlação entre incidência e severidade em diversos fitopatossistemas, sendo que essa possibilidade é maior quando os níveis de severidade permanecem baixos.

Avaliaram-se separadamente os efeitos dos tratamentos e das épocas de avaliação nas correlações. Foram feitas 11 análises de correlações, uma para cada tratamento, a partir dos dados de 12 épocas de avaliação. Por outro lado, foram feitas outras 12 análises de correlações, uma para cada época de avaliação, a partir dos dados de 11 tratamentos. Todas as

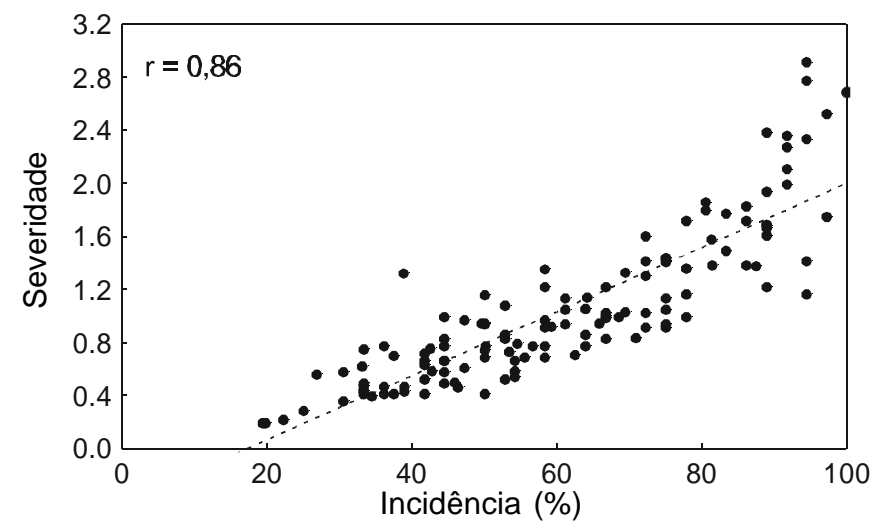

FIG. 1 - Relação entre incidência e severidade da antracnose em frutos de mamão (Carica papaya) após a colheita, em Linhares-ES, em 1997-98. Os dados são médias de quatro repetições e representam 11 tratamentos e 12 épocas de avaliação. correlações foram obtidas a partir de dados de médias de quatro repetições. A correlação entre incidência e severidade de antracnose foi alta e apresentou-se consistente nos diferentes tratamentos e épocas de avaliação. Assim, neste estudo, a severidade fornece informação redundante em relação à incidência de antracnose. Por isso, as análises doravante apresentadas não consideraram a severidade. As correlações entre incidência de podridão peduncular com incidência ou com severidade de antracnose foram baixas ou inconsistentes, nos diferentes tratamentos e épocas de avaliação.

\section{Efeito dos tratamentos e épocas de avaliação na incidência de antracnose e de podridão peduncular em mamão}

Houve efeito significativo $(\mathrm{P}<0,05)$ de tratamentos e de épocas de avaliação na incidência de antracnose. Porém, não houve interação significativa $(\mathrm{P}>0,05)$ entre esses dois fatores, pelo teste F. Não houve redução significativa da incidência de podridão peduncular com a aplicação de fungicidas no campo (Tabela 1). Alvarez et al. (1977) observaram redução de $24 \%$ e $43 \%$ da incidência de podridão peduncular causada por C. gloeosporioides e por P. caricaepapayae com o uso de aplicações bissemanais de chlorothalonil e benomyl, respectivamente. Hunter \& Buddenhagen (1972) também verificaram redução da incidência de podridão peduncular, causada principalmente por $P$. caricae-papayae, com o uso de maneb.

Com exceção dos fungicidas tebuconazole e triadimenol, todos os demais diferiram significativamente ( $\mathrm{P}$ $<0,05)$ da testemunha, reduzindo de 26,4 a $41,2 \%$ a média geral da incidência de antracnose, em relação à testemunha (Tabela 1), considerando as 12 épocas de avaliação. Esses dois fungicidas, haviam apresentado eficiência in vitro e em

TABELA 1 - Efeitos de fungicidas na incidência de antracnose e de podridão peduncular em frutos de mamão (Carica papaya), após a colheita

\begin{tabular}{|c|c|c|c|}
\hline Tratamento & $\begin{array}{l}\text { Dose i.a. } \\
\left(\mathrm{mg.l}^{-1}\right)\end{array}$ & $\begin{array}{c}\text { Antracnose } \\
(\%)\end{array}$ & $\begin{array}{c}\text { Podridão } \\
\text { peduncular } \\
(\%)\end{array}$ \\
\hline Chlorothalonil SC & 2000 & $49,11 \mathrm{a}^{1}$ & 81,77 a \\
\hline Chlorothalonil PM & 1500 & $52,85 \mathrm{ab}$ & $77,28 \mathrm{a}$ \\
\hline $\begin{array}{l}\text { T. metílico + } \\
\text { chlorothalonil PM }\end{array}$ & $400+1000$ & $53,40 a b$ & 80,44 a \\
\hline $\begin{array}{l}\text { Chlorothalonil + } \\
\text { ox. de cobre PM }\end{array}$ & $875+1050$ & $54,86 \mathrm{ab}$ & 88,91 a \\
\hline Iminoctadine F & 300 & $56,42 \mathrm{ab}$ & 83,51 a \\
\hline Fluazinam SC & 500 & $57,51 \mathrm{ab}$ & 82,78 a \\
\hline Tolylfluanid PM & 750 & $59,80 \mathrm{ab}$ & 86,86 a \\
\hline T. metílico PM & 700 & $61,45 \mathrm{ab}$ & 84,83 a \\
\hline zole CE & 200 & $69,50 \quad b c$ & 83,76 a \\
\hline Triadimenol CE & 250 & 71,17 bc & 89,47 a \\
\hline Testemunha & --- & 83,50 & $90,55 \mathrm{a}$ \\
\hline
\end{tabular}

${ }^{1}$ Médias seguidas de letras diferentes, na coluna, diferem entre si pelo teste Tukey $(\mathrm{P}<0,05)$. Previamente às análises, os dados de incidência foram transformados para $\operatorname{arcoseno}(\mathrm{x} / 100)^{1 / 2}$. 
pós-colheita (Liberato \& Tatagiba, 2001). Chlorothalonil, aplicado isoladamente ou em mistura com tiofanato metílico ou oxicloreto de cobre, proporcionou as maiores reduções na incidência da antracnose (Tabela 1).

$\mathrm{Na}$ terceira época de avaliação, caracterizada pela ausência de chuvas em um período de 18 dias que a antecedeu, o chlorothalonil chegou a reduzir $73,6 \%$ a incidência da antracnose. Alvarez et al. (1977) observaram redução de até 98\% da incidência de antracnose com pulverizações bissemanais de chlorothalonil. Solano \& Arauz (1995) observaram que o chlorothalonil, a $2630 \mathrm{mg} . \mathrm{l}^{-1}$ i.a., foi um dos fungicidas que mais reduziu a intensidade de antracnose em mamão. Esse fungicida, embora seja ineficiente na redução do crescimento micelial do patógeno (Liberato \& Tatagiba, 2001), é altamente eficiente na redução da germinação de conídios de C. gloeosporioides (Tong-Kwee, L. \& Ooi-Choi, 1986), o que pode explicar a sua eficiência, quando aplicado no campo. No entanto, a sua recomendação, depende do seu registro para uso na cultura do mamoeiro.

Tiofanato metílico associado a chlorothalonil apresentou 36,0\% de redução da incidência de antracnose, a qual pode ser atribuída principalmente a esse último fungicida. Pois, quando aplicados isoladamente, tiofanato metílico reduziu $26,4 \%$ e chlorothalonil, $41,2 \%$ da incidência em relação à testemunha (Tabela 1). No presente estudo, não foram observados sintomas visíveis de fitotoxidez em plantas ou frutos.

Fungicidas benzimidazóis, como o benomyl e o thiabendazole, já foram reportados como eficientes no controle da antracnose do mamoeiro, aplicados em condições de campo, ou em pós-colheita (Quimio et al., 1975; Bolkan et al., 1976; Alvarez et al., 1977; Couey et al., 1984). Uma possível explicação para a pequena eficiência do tiofanato metílico, no presente trabalho, pode ser o surgimento de populações do patógeno resistentes a esse grupo de fungicidas, fato esse já detectado com relação ao thiabendazole (Astua et al., 1994) e ao benomyl (Ventura \& Balbino, 1995). Trabalhos mais recentes de controle da antracnose do mamoeiro têm revelado a ineficiência dos benzimidazóis, aplicados em condições de campo (Solano \& Arauz, 1995) ou em póscolheita (Sepiah et al., 1991; Liberato \& Tatagiba, 2001). A resistência a um desses fungicidas implica em resistência cruzada aos demais fungicidas desse grupo (Delp, 1980). Isto foi observado na Costa Rica por Astúa et al. (1994), onde isolados de C. gloeosporioides de mamão, obtidos em áreas pulverizadas continuamente com benomyl apresentaram resistência ao thiabendazole.

A aplicação de fungicidas no campo, embora reduza a intensidade da doença (Alvarez et al., 1977), não dispensa a adoção de medidas de controle em pós-colheita, tais como o tratamento térmico e a quimioterapia (Alvarez \& Nishijima, 1987). O tratamento térmico visando ao controle de doenças (imersão em água a $48-49^{\circ} \mathrm{C}$ por $20 \mathrm{~min}$ ) em frutos destinados à exportação via marítima, reduz a incidência de podridão peduncular, mas é insuficiente no controle da antracnose, em condições de alta incidência da doença, sendo necessário, associá-lo ao uso de fungicidas (Couey et al., 1984; Nishijima et al. 1992). Devido a relativa resistência do patógeno aos tratamentos térmicos, por causa da sua fase quiescente, a prevenção da infecção dos frutos no campo, no transporte e no armazenamento, assume fator de grande importância no controle da doença.

\section{Relação entre condições metereológicas e incidência de antracnose em mamão}

Frutos inoculados e incubados a temperaturas de 20 a $40{ }^{\circ} \mathrm{C}$ desenvolveram a doença (Quimio, 1973), sendo maior a severidade entre 25 e $30{ }^{\circ} \mathrm{C}$ (Gupta \& Pathak, 1990). Entre 20 de agosto de 1997, data que antecede em 15 dias a primeira colheita de frutos para avaliação dos efeitos de tratamentos, e 20 de março de 1998, a incidência de antracnose em frutos de mamão foi alta, variando de 68,5 a $100 \%$ no tratamento testemunha (Figura 2d). Nesse período de 213 dias, as condições meteorológicas geralmente foram favoráveis ao desenvolvimento da doença. A temperatura oscilou entre 12 e 37 ${ }^{\circ} \mathrm{C}$, com média de $23,5{ }^{\circ} \mathrm{C}$. A precipitação pluvial alcançou 647,6 mm, distribuída em 37 dias, com variação de 0,6 a $76 \mathrm{~mm}$ diários. A média geral da umidade relativa do ar foi $78,7 \%$, com médias diárias de 66,8 a 95,0\%. Houve 921 horas de molhamento, ou seja, $24,1 \%$ do período monitorado, que foi de 159 dias (Figura 2). Em 90,7\% do período com molhamento, a temperatura oscilou entre 15 e $25{ }^{\circ} \mathrm{C}$, com média de $20,3{ }^{\circ} \mathrm{C}$ (Figura 3).

O período com maior precipitação pluvial foi de novembro a 15 de janeiro: $505 \mathrm{~mm}$ em 16 dias de chuva (Figura 2c). Este período coincide com a maior incidência de antracnose (Tabela 2) e com a menor eficiência dos fungicidas (Figura 2d). Em três das quatro épocas de avaliação nesse período, o tratamento mais eficaz reduziu apenas 25,7 a 29,4\% a incidência de antracnose. Duas explicações são possíveis para tanto. A primeira é que as chuvas podem ter reduzido

TABELA 2 - Efeitos de épocas de avaliação na incidência de antracnose e de podridão peduncular em frutos de mamão (Carica papaya), após a colheita, em 1997-98

\begin{tabular}{|c|c|c|}
\hline $\begin{array}{l}\text { Época de } \\
\text { avaliação }\end{array}$ & Antracnose (\%) & $\begin{array}{c}\text { Podridão } \\
\text { peduncular }(\%)\end{array}$ \\
\hline $1(246)$ & $56,07 \quad$ bc $^{2}$ & $95,45 \quad f$ \\
\hline $2(275)$ & 57,80 bc & 94,21 \\
\hline $3(290)$ & $36,99 \mathrm{a}$ & $64,45 \mathrm{ab}$ \\
\hline $4(303)$ & $59,59 \quad \mathrm{c}$ & 87,37 de \\
\hline $5(321)$ & 79,29 & 93,43 \\
\hline $6(336)$ & 52,27 bc & 74,24 bc \\
\hline $7(357)$ & 87,87 de & 91,16 \\
\hline $8(12)$ & 89,64 & 94,95 \\
\hline $9(26)$ & 54,79 bc & 89,64 \\
\hline $10(48)$ & 56,06 bc & 84,34 \\
\hline $11(62)$ & $43,49 \mathrm{ab}$ & 56,43 a \\
\hline $12(79)$ & 56,59 bc & 89,05 \\
\hline
\end{tabular}

${ }^{1}$ Data Juliana (1997-98) entre parênteses.

${ }^{2}$ Médias seguidas de letras diferentes, na coluna, diferem entre si pelo teste Tukey ( $\mathrm{P}<0,05)$. Previamente às análises, os dados de incidência foram transformados para arcoseno $(\mathrm{x} / 100)^{1 / 2}$ 

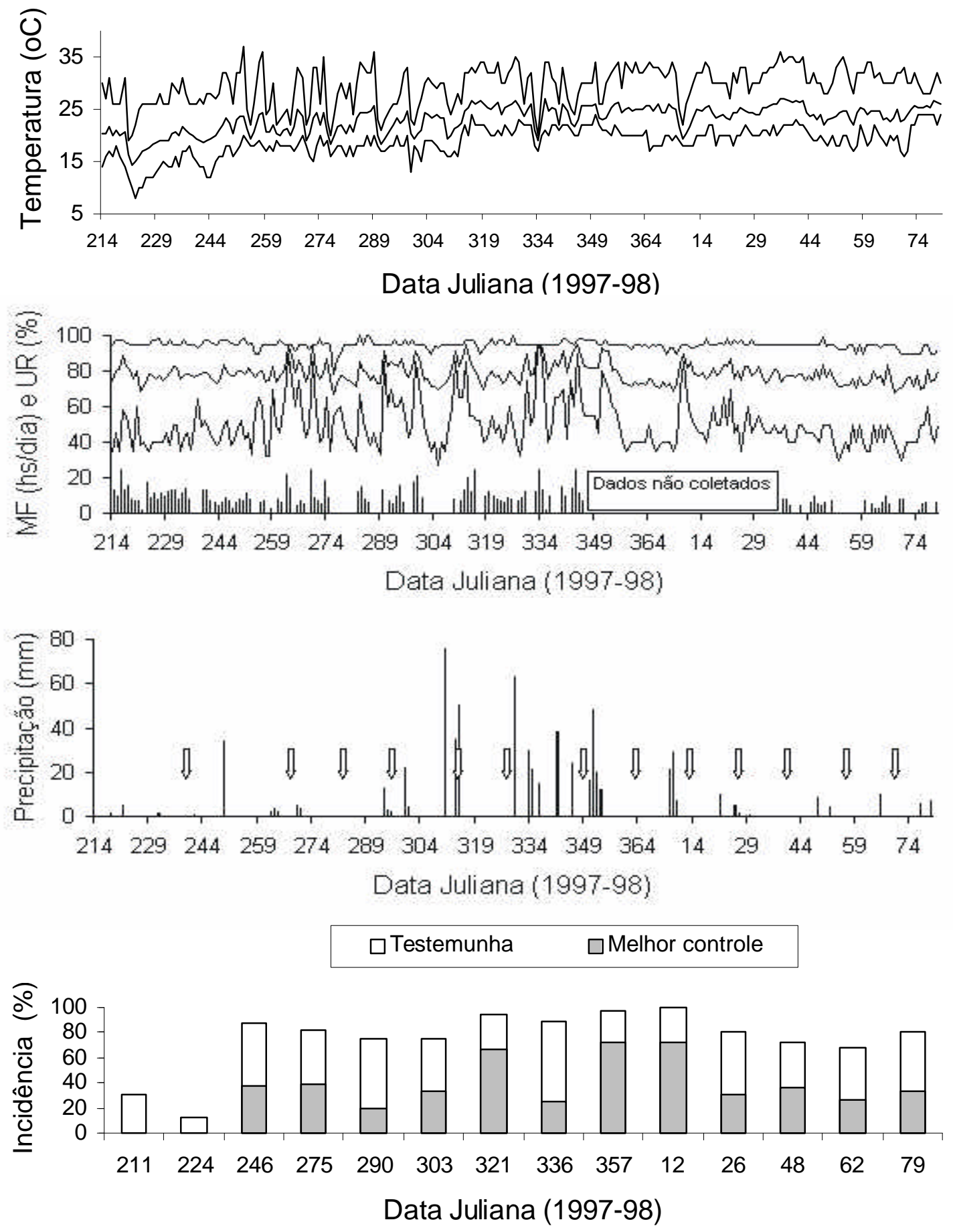

FIG. 2 - Temperaturas máxima, média e mínima (A), molhamento (MF) (barra) e umidade relativa do ar máxima, média e mínima (linhas) $(B)$, precipitação $(C)$ e incidência de antracnose em mamoeiro (Carica papaya) na testemunha e no tratamento com fungicida que proporcionou melhor controle (D). As setas indicam os dias das pulverizações com fungicidas. Nos dias 211 e 224 só foi avaliada a testemunha.

o depósito dos fungicidas da superfície dos frutos, uma vez que o chlorothalonil, que foi o mais eficiente neste estudo, é um fungicida protetor. Contradiz essa explicação o fato que na data juliana 336 não houve redução da eficiência dos fungicidas, apesar da pulverização ter sido realizada oito dias antes dessa colheita e de ter chovido $114 \mathrm{~mm}$ nesse intervalo de tempo. São necessários estudos mais detalhados sobre os efeitos do volume das chuvas diárias, sua intensidade $\left(m m \cdot h^{-1}\right)$ e espaço de tempo entre a pulverização e as chuvas posteriores na redução da eficiência dos fungicidas. A 


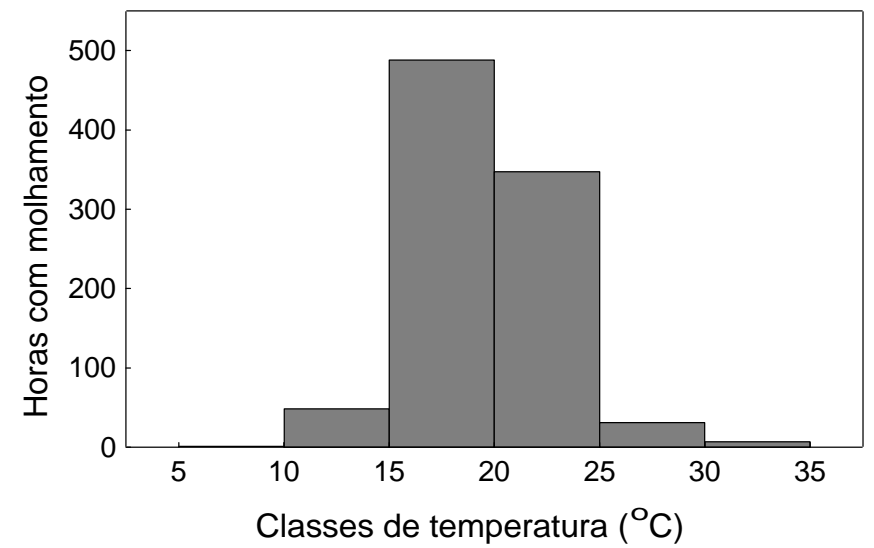

FIG. 3 - Período com molhamento e distribuição da temperatura.

segunda possível explicação, que não elimina a primeira, para a ocorrência de maior incidência de antracnose e menor eficiência dos fungicidas nesse período considerado, é o fato da chuva aumentar a dispersão de inóculo do patógeno, conídios, no pomar. Na Costa Rica, Durán et al. (2000) observaram que, na época chuvosa, a produção de conídos nos pecíolos é 6,6 vezes maior e sua dispersão no pomar é 16 vezes maior que na época seca. No Espírito Santo, tem-se observado elevada incidência da antracnose nos meses quentes e úmidos do ano (outubro a março), como constatado neste estudo. Essa época coincide com a maior produção de frutos. Em períodos secos e de temperaturas baixas, ocorre menor intensidade da doença. A principal fonte de inóculo no pomar são lesões em folhas senescentes (Hunter \& Buddenhagen, 1972 e Durán et al., 2000). Os conídios, produzidos em acérvulos, constituem o inóculo do patógeno e são dispersos principalmente por respingos de chuva ou água de irrigação.

Caso uma dessas explicações, ou ambas, estejam corretas, isso implicaria em que a infecção que ocorre na fase final de desenvolvimento do fruto (uma ou duas semanas antes da colheita) é que determina a intensidade de antracnose póscolheita, contradizendo os resultados observados por Hunter \& Buddenhagen (1972) e Alvarez et al. (1977). Hunter \& Buddenhagen (1972) observaram que a incidência de antracnose foi maior quando somente a porção inferior da coluna de frutos na planta foi pulverizada com fungicida, em comparação à pulverização na porção superior ou na coluna completa de frutos. Alvarez et al. (1977) observaram que, mesmo 12 semanas após a última das aplicações bissemanais de fungicidas, os frutos colhidos apresentavam grande redução da incidência de antracnose em relação à testemunha. Esses frutos tinham recebido, em média, seis aplicações de fungicida nas primeiras 12 semanas de seu desenvolvimento. No presente estudo, os frutos receberam de seis a dez aplicações de fungicidas, dependendo da época de avaliação, durante o seu desenvolvimento. A pequena eficiência dos fungicidas na quinta, sétima e oitava época de avaliação está em desacordo com o observado por esses autores.

Recentemente foi detectada a forma perfeita desse patógeno, Glomerella cingulata (Ston.) Spauld. \& Schrenk, em pomares de mamoeiro no município de Linhares-ES (Costa et al., 2001). Esse fato pode alterar as características de epidemias da doença, uma vez que seus ascosporos são dispersados pelo vento, não necessitando de água para tal. No Havaí, Hunter \& Buddenhagen (1972) observaram que, durante os meses de inverno, a abundância de ascosporos de Glomerella sp. capturados esteve associada à alta incidência da doença nos frutos.

Uma hipótese a ser investigada na tentativa de explicar os fatos observados no presente estudo é se ascosporos do patógeno infetam o fruto preferencialmente nos estágios finais de seu desenvolvimento, uma vez que os conídios infetam o fruto na maior parte de seu período de desenvolvimento (Dickman \& Alvarez, 1983; Durán et al., 1999) e, aparentemente, a infecção na primeira metade deste período é a mais importante (Hunter \& Buddenhagen, 1972; Alvarez et al., 1977).

\section{AGRADECIMENTOS}

Os autores expressam seus agradecimentos ao Engoo. Agro Fabrício Carrareto Barreto, que cedeu parte de sua lavoura para a condução do experimento.

\section{REFERÊNCIAS BIBLIOGRÁFICAS}

ALVAREZ, A.M., HYLIN, J.W. \& OGATA, J.N. Post harvest diseases of papaya reduced by biweekly orchard sprays. Plant Disease Reporter 61:731-735. 1977.

ALVAREZ, A.M. \& NISHIJIMA, W.T. Post harvest diseases of papaya. Plant Disease 71:681-686. 1987.

ASTUA, G., ARAUZ, L.F. \& UMAÑA, G. Sensibilidad reducida al tiabendazole em Colletotrichum gloeosporioides aislado de papaya. Agronomia Costarricense 18:35-39. 1994.

BALBINO, J.M.S. Efeitos de hidrotermia, refrigeração e ethephon na qualidade pós-colheita do mamão (Carica papaya L.). (Tese de Doutorado). Viçosa. Universidade Federal de Viçosa 1997. $104 \mathrm{p}$.

BOLKAN, H.A., CUPERTINO, F.P., DIANESE, J.C. \& TAKATSU, A. Fungi associated with pre- and post harvest fruit rots of papaya and their control in Central Brazil. Plant Disease Reporter 60:605-609. 1976.

COSTA, H., VENTURA, J.A., RODRIGUES, C.H. \& TATAGIBA, J.S. Ocorrência e patogenicidade de Glomerella cingulata em mamão no Norte do Estado do Espírito Santo. Fitopatologia Brasileira 26:328. 2001 (Resumo).

COUEY, H.M., ALVAREZ, A.M. \& NELSON, M.G. Comparison of hot-water spray and immersion treatments for control of post harvest decay of papaya. Plant Disease 68:436-437. 1984.

DELP, C.J. Coping with resistance to plant disease control agents. Plant Disease 64:652-657. 1980.

DICKMAN, M.B. \& ALVAREZ, A.M. Latent infection of papaya caused by Colletotrichum gloeosporioides. Plant Disease 67:748-750. 1983.

DURÁN, A., MORA, D. \& RAMÍREZ, L. Los peciolos de la papaya como fuente de inóculo de la antracnosis y su eliminación como práctica de control. Agronomía Mesoamericana 11:714. 2000. 
DURÁN, A., MORA, D. \& CHAVARRÍA, E. Determinación de la edad susceptible del fruto de la papaya (Carica papaya L.) a la antracnosis (Colletotrichum gloeosporioides Penz.). Agronomía Mesoamericana 10:1-6. 1999.

FA0. A folder available on the Internet (last updated: 22 december 2000, url: http://apps.fao.org).

GUPTA, A.K. \& PATHAK, V.N. Epidemiology and management of papaya fruit rots. Summa Phytopathologica 16:92-105. 1990.

HUNTER, J.E. \& BUDDENHAGEN, I.W. Incidence, epidemiology and control of fruit diseases of papaya in Hawaii. Tropical Agriculture 49:61-71. 1972.

LIBERATO, J.R. \& COSTA, H. Incidência de antracnose e podridão peduncular em frutos de mamoeiro em Linhares - ES. Fitopatologia Brasileira 22:276. 1997 (Resumo).

LIBERATO, J.R. \& TATAGIBA, J.S. Avaliação de fungicidas in vitro e em pós-colheita para o controle da antracnose e da podridão peduncular em frutos de mamão. Summa Phytopathologica 26:409-414. 2001.

NISHIJIMA, K.A., MIURA, C.K., ARMSTRONG, J.W., BROWN, S.A. \& HU, B.K.S. Effect of forced, hot-air treatment of papaya fruit on fruit quality and incidence of post harvest diseases. Plant Disease 76:723-727. 1992.

QUIMIO, T.H. Temperature as factor for growth and sporulation of anthracnose organism of papaya. Philippine Agriculturist 57:245-253. 1973

QUIMIO, T.H., PORDESIMO, A.N. \& QUIMIO, A.J. Control of papaya fruit rots by post harvest dip in thiabendazole. The Philippine Agriculturist 59:7-11. 1975.

SEEM, R.C. Disease incidence and severity relationships. Annual Review of Phytopathology 22:133-150. 1984.

SEPIAH, M., SUBKI, A. \& LAM, P.E. Fungicides for post harvest control of Colletotrichum spp. in Eksotika papaya. Asean Food Journal 6:14-18. 1991.

SOLANO, V. \& ARAUZ, L.F. Combate de antracnosis en frutos de papaya mediante aplicaciones de fungicidas en el campo en la zona atlântica de Costa Rica. Agronomia Costarricense 19:2530. 1995.

STATSOFT, INC. Statistica for Windows [Computer program manual]. Tulsa, OK: StatSoft Inc., 2000. (http//www.statsoft.com).

TONG-KWEE, L. \& OOI-CHOI, W. Effects of selected fungicides in vitro on the mango anthracnose pathogen, Colletotrichum gloeosporioides. Fitopatologia Brasileira 11:67-74. 1986.

VENTURA, J.A. \& BALBINO, J.M.S. Resistência do agente etiológico da antracnose do mamoeiro ao benomyl, no Estado do Espírito Santo. Fitopatologia Brasileira 20:308. 1995 (Resumo). 